\title{
Para una ontología de la violencia. Paisaje y mestizaje en la comprensión integral del conflicto que piensa un posconflicto desde las Humanidades*
}

JUAN CEPEDA H. ${ }^{*}$

DIANA MARCELA MAYORGA VALENCIA ${ }^{* * *}$ ANDREA TORRIJOS SUÁREZ ${ }^{* * *}$

* Este artículo es un aporte a la comprensión del conflicto y posconflicto nacionales, a partir del proyecto de investigación "Ontología del paisaje en Rodolfo Kusch" que está avanzando el SEmillero MEtafísica y ONtología: SEMEyON durante 2016-2017.

** Licenciado en Filosofía y Letras, Magister en Filosofía Latinoamericana, y Doctor en Filosofía de la Universidad Santo Tomás. Director del grupo de investigación tlamatinime y de su SEmillero MEtafísica y ONtología: SEmeyon. Correo electrónico: juancepeda@usatotomas.edu.co.

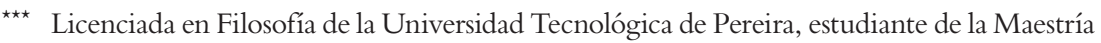
en Filosofía Latinoamericana de la Universidad Santo Tomás, e integrante del SEmillero MEtafísica y ONtología: SEMEyON. Correo electrónico: mayorguit@gmail.com.

${ }^{\star \star \star \star}$ Licenciada en Filosofía y Letras, estudiante de la Maestría en Filosofía Latinoamericana de la Universidad Santo Tomás e integrante del SEmillero MEtafísica y ONtología: SEMEyON. Correo electrónico: antretorrijos@gmail.com. 


\section{INTRODUCCIÓN}

La comprensión del conflicto nacional exige una mirada amplia y profunda a la realidad diversa y compleja de nuestras violencias. ¿Cómo se constituye el paisaje de esta realidad social y hasta dónde se enraíza?, o sea: ¿hasta dónde las coordenadas de nuestras agresividades y violencias apuntan a realidades no visibilizadas por los discursos tradicionales? y ¿cómo el paisaje y el mestizaje podrían ayudarnos a comprender nuestra realidad?, son interrogantes que enriquecen el proyecto de investigación que desde 2016 avanzamos al interior del semillero SEMEyON. El proceso estructural y vital del conflicto a la violencia institucionalizada y de esta al posconflicto merecen un estudio mucho más amplio de lo que comúnmente se señala. La ciudad y el propio estado parece ajeno a todo el proceso, como si se tratara de un tema insustancial o implícito en las agendas oficiales, pasa de largo como cualquier otro tópico del diario vivir, pese a que aproximadamente el $75 \%$ de la población colombiana es eminentemente urbana (DANE, 2014), muy por encima del promedio mundial que se ha calculado en un 51,3\% según las Naciones Unidas (ONU, 2014) parecen pertenecientes a otra realidad aledaña a la nuestra. Ahora bien, el conflicto al ser una constante social en nuestro país se ha convertido en un tema regular que acompaña la media mañana de los ciudadanos, el colombiano se rodea a diario de innumerables razones, para pelear contra el mundo, pero más de la mitad de ellas son erradas o carecen de fundamentos por la falta de información, pues se confunden con las emisiones deportivas, de farándula, de economía y de salud, como si la guerra fuera un tema más en los anaqueles de un supermercado, en dónde el estar acostumbrado a progresar a través de la violencia se convierte en una actividad regular para el colombiano. Campo y ciudad, ciudadano e indígena, barbarie y urbanidad, resultan siendo categorías mestizas que conviven cotidiana y socialmente muchas de las veces de forma agresiva, impositiva y violenta. Por ello echamos mano de un estudio que sobre el paisaje adelantara a mediados del siglo XX el filósofo argentino Rodolfo Kusch, y a partir de él buscamos comprender algunas variables que podrían posibilitar mejores o, por lo menos, diversas soluciones al largo conflicto sufrido por los colombianos. Presentamos, entonces, el marco teórico fundamentado en este estudio de Kusch; luego, tratamos de analizar la situación de conflicto 
como se nos ha ofrecido históricamente; en seguida, más que un análisis de resultados, que por ahora es imposible de obtener, proponemos algunas reflexiones que, desde las Humanidades, buscan aportar elementos de comprensión integral a la situación de conflicto y posconflicto nacional; y finalmente, se esboza alguna conclusión que quisiera mejor abrir nuevos horizontes de investigación y estudio de la realidad aquí presentada.

\section{MARCO TEÓRICO}

El paisaje social de nuestras violencias en Colombia y América Latina exige un marco teórico que posibilite la comprensión de dicha realidad desde categorías adecuadas a esta situación de conflicto encarnado por varias generaciones. La bibliografia sobre el conflicto, la guerra y la violencia es cada vez más amplia, pero la bibliografía sobre la comprensión de los presupuestos sociales, psicológicos, e histórico-culturales, más allá de propuestas interpretativas meramente teóricas, es bastante pobre. Los integrantes del SEmillero MEtafísica y ONtología: SEMEyON le estamos apostando a un proyecto sobre "Ontología del paisaje en Rodolfo Kusch" que avanzamos durante 2016-2017. Bajo este horizonte abierto por las investigaciones in situ del filósofo argentino, queremos preguntar por la posibilidad de comprensión del fenómeno de nuestros conflictos tanto a nivel nacional como latinoamericano, por lo que limitaremos el marco teórico a la obra de Kusch que hemos estado estudiando durante un año en SEMEyON: La seducción de la barbarie.

Rodolfo Kusch nos introduce en su texto de 1953 analizando la experiencia porteña de estar acodado a la mesa en un café de la ciudad de Buenos Aires mirando por la ventana, mientras se vivencia un sentido de lo más auténtico, de lo más sincero y transparente consigo mismo, ya libre de las ficciones propias de la vida laboral y tomando cierta distancia de costumbres que la vida urbana nos va imponiendo. Allí, a solas, junto a la ventana, con la mirada como perdida entre las calles de la gran ciudad, se experimenta la falta de conexión entre la vida personal (verdadeante consigo mismo) y la forma de ser ciudadana, entre la vida cotidiana personal y los menesteres urbanos, entre el espíritu que nos anima vitalmente y ese afán que nos ahoga cumpliendo horarios, desempeñando oficios 
mecánicamente, y aparentando relaciones sociales a veces sin fondo alguno. Aunque se da en pensar en ese momento que lo que se está sintiendo al liberarse de tantos quehaceres y compromisos ciudadanos es una experiencia como auténtica, genuina, existencial, de encuentro consigo mismo, devienen diversos interrogantes:

¿Será que habremos olvidado la verdad de Perogrullo de que siempre nos encontramos en un "aquí y ahora", perfectamente perfilados y con una infinita riqueza de contenido pero cuyo análisis nos lo impide la ciudad? ¿O no será, también, que no tenemos con qué pensarlo, para así traerlo cerca, ponérnoslo delante y vivir la situación con el beneficio de verla desde la inteligencia y desde el mundo de las relaciones? ¿Y, más aún, hacer esto con el hondo convencimiento de abarcar todos los contenidos profundos de este "aquí y ahora", consistente en el café, el ventanal y el transeúnte, y con la emoción que se siente en un poema ${ }^{1}$, en un acorde o en un crepúsculo? (Kusch, 2000, p. 18)

Pero aunque el transeúnte, más allá de la ventana, se aleja; y el acorde, por ejemplo de un tango, se va desvaneciendo, igual que el crepúsculo; aunque esto es una evidencia ineludible, ahí se nos pone de presente la ciudad, se nos afirma frente a nosotros, y se convierte en una verdad de razón que nos entretiene y nos aleja de la verdad íntima que acababa de asomarse perpleja más acá de la ventana, acodados en la mesa a la espera de un café. Entonces se da cuenta de la escisión entre la vida urbana e inteligente de la ciudad y la vida personal e íntima con la que uno puede estar más a gusto pero no se puede realizar, aun a pesar de ser la vida propia, de donde Kusch deduce que la causa de dicha escisión es precisamente la ciudad. "Llegamos así a la conclusión de que vivimos dos verdades, una ficticia, que percibimos, y otra real que apenas alcanzamos a vivir" (Kusch, 2000, p. 20).

El primer capítulo de esta obra ya lleva un título bastante sugestivo: metafisica vegetal ${ }^{2}$. E inicia con una sentencia que sólo de forma tranquila

1 El subrayado es nuestro.

2 El texto de este capítulo había sido escrito en 1952, y se publicó originalmente el 4 de mayo de ese año en el suplemento cultural del periódico La Nación de Argentina. 
se puede asimilar: "el paisaje se agiganta en el largo trayecto que va de la palabra a su realidad" (Kusch, 2000, p. 25).Y es que hablar de paisaje resulta poco cuando no se ha estado en pie o sobre caballo observando hacia todo lado y encontrarse a solas en medio de la pampa o de la puna, o cuando no se ha por lo menos visitado y sentido la selva amazónica, o cuando no se ha anonadado el ser a las alturas de Machu Picchu, perdiéndose no solamente en el infinito geográfico sino en el infinito existencial extáticamente, asombrado de que en verdad no somos nada y que solamente hacemos parte puntual del real y verdadero paisaje que se ensancha ahora también en nuestra mente al tratar de comprenderlo. La investigación académica se equivoca cuando cree que somos nosotros los observadores de la realidad, insuflándonos el ego de quien considera manejar las diversas variables hipotéticas con que se construyen cada vez más nuevas teorías que podrían tal vez ahora sí explicar todos los secretos de lo real, de lo que es, cuando, al contrario, lo que se vivencia en América Latina, es que el paisaje, o si se quiere: la madre Tierra, es la que aguarda a veces no tan silenciosa señalando nuestros pasos muchas veces equívocos, siendo más bien nosotros los observados cual don Segundo Sombra o Arturo Cova. La palabra paisaje termina sin decir esa hondura o grandeza que el paisaje latinoamericano no deja de mostrar impálabre; es más, hay algo como escondido en ese paisaje, que aunque no visible se hace sentir, que se nos impone al encontrarnos con él, que atemoriza, que se experimenta como vértigo existencial, y que va hundiéndose en nosotros, trastocando nuestro propio ser.

El latinoamericano siente con fuerza esa ambivalencia de su ser debido a que se le ha desenraízado con violencia, se le ha amputado su conexión con la tierra, se le ha impuesto otro suelo (de cemento) desde el que emergen no árboles sino edificios y por entre los que uno (a diferencia de los árboles) se va moviendo, en aparatos mecánicos no creados ni diseñados desde nuestra cultura sino de manera impuesta. Pero, de fondo, las raíces buscan su alimento. "Como no puede escapar a su sentimiento vegetal, siente que la cualidad motriz de su cuerpo no es más que ficción, un simple proyecto para la creación de un mundo móvil" (Kusch, 2000, p. 35). Dentro de sí está la fuerza del árbol para tener su fijeza, está la fuerza del paisaje huyendo de las definiciones, y está el ímpetu del demonismo que clama una realización espiritual. El paisaje aparentemente 
estático deviene amorfo en la naturaleza humana que, aun desarraigada, y precisamente por ello, busca extender su ramaje, también amorfo, en medio de lo urbano, en la ciudad, bajo la forma de mestizaje: según Kusch su primer vestigio fue la serpiente emplumada con continuidad y perpetuación ahora en la actual ciudad.

Entre la ficción de la ciudad y la realidad subyacente que se nutre de lo telúrico se da una distancia que rompe la armonía existencial y hace patente esa angustia desequilibrante con la que no se pueden aceptar las formas extrañas impuestas. Lo autóctono, en América Latina, está dado en ese demonismo aborigen del que germina un sentimiento vital de pertenencia ecológica a un suelo, y que reacciona ante el ser impuesto, ante las formas apolíneas de la pulcritud y el orden, irónicamente, soslayando su sentido ontológico de intenciones universales.

¿Cómo se supera dicha escisión? De ello trata Kusch en el cuarto capítulo de la primera parte de La seducción de la barbarie. A diferencia de Europa, en América Latina la ciudad se asemeja al consciente (social, en este caso), a la acción, a la luz, a lo formalmente definido (y con esto, al ser, no nuestro, sino advenido y en consecuencia, para nosotros, falso); lo que queda por fuera de la ciudad es como el inconsciente, lo pasivo, oscuridad, y sin formas ni definiciones. En síntesis, a nivel continental, a nivel geocultural, se evidencia y radicaliza esa escisión que ya se venía exponiendo.

Pero aunque radicalizada geoculturalmente, dicha escisión deviene en un mismo ser, en el mestizo. Éste participa de ambas índoles: por un lado se encuentra su faceta vegetal, demoniaca, fatalista, y como estática; por otro lado está una conciencia activa, lógica, constructora, aunque foránea. En verdad, ese lado telúrico "no concilia con la índole de la acción, pero como tampoco la rechaza se mantiene en el inconsciente de nuestro hacer, en el tabú inmoral de nuestra herencia europea" (Kusch, 2000, p. 63), desde la que se busca entroncar nuestra historia profunda (autóctona, enraízada, vegetal, y no escrita) en la suya pretendidamente universal y escrita, obviamente, por intelectuales en las grandes ciudades. El mestizo que da crédito más a su ímpetu demoniaco que a la intelección de una realidad apolínea, jamás se satisface con esa mirada pulcra, bien definida y conceptualizada, fruto del sentido de la visión ahora educado racionalmente; él confia más en lo posible, en la armonía de lo escindido, en la voluptuosidad del paisaje, en la seducción de 
la barbarie. El mestizo latinoamericano "relega su hacer al inconsciente de su acción asociándose al paisaje, a la posibilidad pura en que proyecta, fantasmagórica, una armonía que siempre posterga" (Kusch, 2000, p. 65), una armonía solamente comprensible desde lo vegetal, desde la vitalidad autóctona que ejerce una cierta gravidez sobre las cosas cual nada potencial, esfera primordial de todas las posibilidades. "Y desde la fe en esa posibilidad se marca la distancia que media entre la provincia y la capital o sea entre lo aborigen y lo foráneo, entre la realidad auténtica y la realidad ficticia, entre el ente y el ser" (Kusch, 2000, p. 68).

La segunda parte de este libro se centra en la historia; ésta tiene que ver con el pasado, con ese girón de realidad que no había sido aprehendido. Pero, en primer término, la historia tiene que ver con el presente, dice Kusch: poner en juego la verdad del presente.

La función primordial de la historia estriba en crear una primera autoconciencia de la comunidad, el primer atisbo de su integridad óntica como pueblo, porque al rastrear el ser y el no ser de ella en el tiempo recoge todas las fuerzas del pasado, todos los grados de libertad dejados en el pasado. (Kusch, 2000, p. 71)

En la historia se pone de presente, entonces, el horizonte ontológico de un pueblo, horizonte en el que se constituye la autenticidad de su ser. Es un ejercicio existencial. "La normalidad mental da la unidad cronológica de nuestra existencia, que a su vez integra la conciencia de nuestro ser, une el ser al tiempo a partir del presente, en función del pasado y en proyección al futuro" (Kusch, 2000, p. 72). Sin embargo, entre la fijación que va dando el presente y las posibilidades que pudieron darse en el pasado, se abre una grieta a la ambivalencia, porque aparece la sinrazón del no ser que viene del pasado y se va diluyendo hacia el futuro, y en medio de este devenir, el mestizo en la ciudad opta por los archivos, que son testimonio de un pasado consciente, sacrificando lo inconsciente, lo no escrito, es decir, lo vegetal de nuestra historia;"allí encubre la angustia que le produce su lejanía del ser, el reconocimiento hondo de la mentira en que vive, y por decirlo en términos existenciales, de su ex-sistencia" (Kusch, 2000, p. 73), aferrándose entonces a la verdad de los archivos y haciendo de la 
historia algo fijo e inamovible. Esa es la historia de los relatos, la historia en la que se cree en la ciudad, que se mantiene porque permite ubicarse en un sentido integral, no importa que sea falso, se mantiene "por motivos ontológicos, por el único fin de sostener la simulación de una integridad, cuyo mecanismo primordial consiste en defender, aunque sin fe, la inteligibilidad del presente contra la tiniebla del pasado" (Kusch, 2000, p. 75).

La verdadera historia, en cambio, debe ser leída en profundidad: en ese pasado de barbarie, en ese inconsciente vegetal que se mantiene en el presente, en esa libertad reprimida que se hace profecía. Es así como se constituye la gran historia, "por cuanto reconquista los trozos del ser, que, por decir así, van quedando en el pasado pero que necesita en la lucha del presente" (Kusch, 2000, p. 79). Una historia que verdadea el demonismo propio que permanece latente en su pasado y en su presente abre posibilidades reales para su futuro liberando toda esa fuerza de barbarie. Si se niega nuestro pasado y presente de barbarie, violencia y conflicto en sus justos aunque crueles límites, no podremos acceder tampoco a las soluciones justas y necesarias que necesitamos para sanar y superar las patologías personales y sociales que hemos venido padeciendo.

\section{ANÁLISIS DE LA SITUACIÓN}

Tanto el conflicto que durante décadas ha pervivido en la sociedad colombiana como el posconflicto y la construcción de paz, requieren pensarse como procesos recíprocamente conectados, esto significa comprender que el posconflicto y la construcción de paz sólo son posibles en la medida que se comprende también la ambivalencia del conflicto, personal y social; sin este agregado conceptual, los esfuerzos por reconciliar, reparar, promover el goce de los derechos y la sana convivencia estarían por fuera de nuestro alcance.

¿Qué hay detrás de los orígenes, las causas, los factores, e inclusive, los impactos del conflicto? ¿Es posible finiquitar el problema respondiendo desde un componente político y social la pregunta por la violencia y su barbarie?, desde este horizonte, encontramos conceptos como territorio, ciudadano, campesino, guerrillero, seguridad, paz, memoria, perdón. Estos términos que en últimas solamente definen personas o cosas quedan tan incompletos y 
generan tantas dudas como el proceso que adelanta el gobierno y la guerrilla colombiana. La incertidumbre de los colombianos ante la reconciliación ha sido constante y notoria, tanto en los resultados del plebiscito en los que el país se mostró dividido como en la desconfianza a raíz de los asesinatos de líderes campesinos (alrededor de 100 en el año 2016) quienes sentaron precedentes a favor de la paz y de la restitución de tierras, como se afirma en el informe de 2017 de la Human Rights Watch Colombia:

Es común que defensores de derechos humanos, sindicalistas, periodistas, líderes indígenas y afrocolombianos, y otros activistas comunitarios sufran amenazas de muerte y otros actos de violencia por parte de guerrillas y grupos sucesores, entre otros. Los actores que cometen actos de violencia contra civiles casi nunca rinden cuentas por sus actos. (versión digital)

¿Cómo abordar, entonces, el posconflicto? ¿Desde una cátedra por la paz? ¿Desde edificios de reconciliación y museos de la memoria? El conflicto tiene su origen en la violencia encarnada que la historia en devenir patentiza existencial y cotidianamente, pero ella misma contiene unos orígenes que, al parecer, se están dejando de lado en la medida que se avanza sobre conceptos culturales elaborados para las clases media y alta de nuestra sociedad, y seguramente de algunas víctimas. A la construcción de la paz le hace falta el cuerpo vivo de las víctimas, la carne signada que por sí misma testimonia el sufrimiento siempre escondido en el pobre, el campesino, el niño, la madre, el adolescente; igualmente, le hace falta la tierra, pero no la que se intercambia sino la que se ama, le hace falta incluir los anhelos, los sentimientos y las pasiones de quienes han acallado sus voces, así como le hace falta sentir la vitalidad natural propia de los indígenas que han ganado un horizonte de comprensión integral, telúrico. No es posible hablar de paz cuando está formal y existencialmente incompleta.

Sin una mirada al trasfondo profundo e íntegro de la violencia que genera el conflicto no es posible hablar verdaderamente de postconflicto porque, de esta manera, no es posible aseverar que estamos un paso más delante de la discordia, solamente "adaptando" otras formas de violencia y, por tanto, otras formas de conflicto. Para ello, es innegable la necesidad de pensar tanto la visión que tradicionalmente ha tenido la violencia como 
la posibilidad de abrirnos a un espacio ontológico que permita reconocer el carácter primario del conflicto y nos lleve a pensar en las acciones a emprender en el posconflicto.

La visión clásica o tradicional de la violencia asociada con el conflicto se encuentra coligada a factores como el uso de la fuerza en el reclutamiento de niños y niñas, el desplazamiento, la expropiación de tierras indígenas y campesinas, la violación de niñas, niños, mujeres y hombres así como de tantas otras violaciones a los derechos humanos.

La autoría y plena responsabilidad de estas graves violaciones masivas y generalizadas a los Derechos Humanos y al Derecho Internacional Humanitario, recae, no sobre individuos, sino sobre grupos armados ilegales y organizaciones criminales identificadas y conocidas: las FARC, el ELN, las Bandas Criminales (BACRIM), y los grupos paramilitares, que han establecido la práctica del reclutamiento y uso de los niños y las niñas dentro de sus objetivos estratégicos como parte de una política metódica, sistemática, deliberada, dirigida contra una población en situación de extrema vulnerabilidad y que golpea, especialmente, a los grupos indígenas. (Springer, 2012, p. 9)

En la historia de Colombia, según está expuesto en el capítulo Los motivos y las transformaciones de la guerra del documento ;Basta ya! Memorias de guerra y dignidad, se muestran que paralelamente a la fundación de las FARC en 1965, brotaron el Ejército de Liberación Nacional - ELN (en 1962) y el Ejército Popular de Liberación - EPL (en 1967), cuyos orígenes se consignan entre los jóvenes habitantes de las ciudades y radicalizados según los lineamientos de las revoluciones cubana y china, y los primogénitos de las antiguas guerrillas gaitanistas del Magdalena medio, el alto Sinú y el valle del río San Jorge (la mayoría de ellos campesinos), inconformes con las restricciones de participación política en el Frente Nacional. El ELN se originó, primordialmente influenciado de la Revolución Cubana, principalmente por el impacto producido por ellas en las juventudes universitarias y de la clase media de los mayores núcleos urbanos de Latinoamérica, aunque también se basó en las luchas de tipo nacional, de guerrillas liberales como las del Magdalena Medio y los Llanos orientales, y con la 
expectativa que se generó en sectores progresistas urbanos colombianos a lo que se llamó la nueva izquierda frente a la inconformidad social. El ELN recogía, además, los calores de la lucha sindical en Barrancabermeja, además de las colonizaciones adelantadas en cercanías de los cauces de los ríos Lebrija, Ermitaño y Catatumbo por campesinos desplazados por la Violencia o atraídos por las posibilidades que ofrecía la extracción de petróleo y la apertura de vías de comunicación, como el ferrocarril Bucaramanga-Puerto Wilches y el del Atlántico. Por supuesto, esta realidad era ajena a la vida de la ciudad, pues pasaba como una acción que no afectaba directamente sus vidas, aunque hacerse ciego ante el hecho implicara de cualquier manera una negación de la realidad.

Ahora bien ese pasado tormentoso, es ahora parte de nuestra historia, claro está que dicha realidad no solo hace parte de nuestro pasado, también es el evidente resultado del presente y los temas de interés del hoy, por ello según el artículo Ciudad y hábitat en el postconflicto en Colombia y el mundo, de la Universidad Nacional del 2015, las negociaciones iniciadas el 18 de octubre del 2012 en la Ciudad de la Habana Cuba entre el gobierno colombiano y las Fuerzas Armadas Revolucionarias de Colombia (FARC) en conjunto a la denominada fase exploratoria hacia el inicio de una negociación con la insurgencia del Ejército de Liberación Nacional (ELN) prometen de alguna manera un acuerdo que les garantice una paz estable y duradera, para lo cual se plantea un escenario que hace indispensable analizar detenidamente esta situación, pues hasta ese momento se habían tratado cinco puntos de la agenda pactada con las FARC: a) una política de desarrollo agrario integral, b) la participación política, c) el fin del conflicto, d) la solución al problema de las drogas ilícitas, y e) la reparación de víctimas. En el caso del ELN para el 2015, aún se estaba definiendo una estructura que adelantara el proceso con el gobierno nacional colombiano, para lo cual se plantearon ocho asuntos importantes:

a) el problema del campo que debe ser reemplazado por una combinación de lo energético (oro, petróleo y carbón) con una propuesta estratégica ambiental, b) la defensa de los recursos naturales y el medio ambiente, c) la participación de la sociedad civil ligada estrechamente a "lo territorial" y a la realización de una "Convención Nacional", d) la atención 
de las víctimas, el fin del conflicto, la refrendación de los acuerdos y el narcotráfico, e) los cambios y reconocimientos de los movimientos rurales y campesinos, f) la ampliación y profundización de la democracia de tal manera que se ofrezcan garantías para el ejercicio de la política, g) la integración de América Latina y la soberanía, y, h) la perspectiva de construir una agenda política pública a partir de lo que se pacte en la negociación. (Bitácora 25, 2015, p. 7)

Ahora bien, esto no quiere decir que el país actual, no esté luchado para salir de la situación en la que se encuentra, el problema está en que lleva tanto tiempo mirando hacia otro lado que ahora que requiere ver con mayo afán lo que ocurre ni siquiera es capaz de reconocer que dejo de mirarse en algún momento a sí mismo, pues de alguna manera al encontrarse en una realidad violenta, pasa desapercibido de lo que le acontece y apenas se percata de aquel rostro que dejo olvidado en el espejo del ático que en algún momento también sufrió y lloró por la crueldad de la violencia y ahora no hace más que repetirse a sí mismo como en un recital de canto, lo que en la administración del expresidente Uribe se dijo del 5 al 12 de febrero del 2001:

1. En Colombia no hay un conflicto armado, sino una democracia legitima defendiéndose de unos grupos terroristas financiados por el narcotráfico. 2- Que precisamente como no hay conflicto, el gobierno no busca la negociación para ponerle fin. Espera que los grupos terroristas cesen unilateralmente sus ataques a la sociedad, para considerar su inserción a la civilidad. Es decir, no cree en negociaciones de paz (Aunque en la actualidad esté en proceso de dialogo con el ELN y en varias oportunidades durante su gobierno lo haya intentado abierta y fallidamente con las FARCEP), sino en desmovilizaciones. 3- Que no hay crisis humanitaria. Cree que los organismos internacionales la han exagerado para justificar sus gastos burocráticos y que, en cambio, no reconocen la enorme mejoría en la protección y atención a las víctimas. 4- Que la cooperación internacional no debe sujetarse al cumplimiento de los Derechos Humanos, sino que, por el contrario, el apoyo al fortalecimiento de las instituciones del Estado es lo que permite el respeto de los 
Derechos Humanos. 5- Que los principios que deben orientar la desmovilización de los grupos armados son credibilidad y equilibrio, más que los principios de justicia, verdad y reparación por los que abogan las ONG y la comunidad internacional. (Trejos, 2008, p. 82)

De acuerdo con el artículo de Luis Fernando Trejos en la revista Encrucijada Americana, desde el Estado resulta más inteligente anular al adversario y negar la existencia del conflicto que afrontar la realidad que acontece, y ataca las causas o factores que de algún modo le dieron vida para desaparecerlos de raíz, posibilitado que se prolongue por más de 40 años. Al parecer, en el proceso de construcción de la identidad nacional se ha dado una perspectiva constructivista, es decir, ha dado mayor importancia a su discurso que a la realidad lo que de alguna manera genera una negación total, como ocurre con el indígena frente al ciudadano.Ya que para ningún gobierno es políticamente funcional reconocer que no es capaz de amparar el monopolio de las armas y el tributo en su región, pues hacerlo sería mostrar incapacidad e ineficacia ante la comunidad nacional e internacional, sin contar la gran cantidad de violaciones a los Derechos Humanos e infracciones al Derecho Internacional Humanitario que cometen agentes del Estado contra la población civil en el marco de operaciones contrainsurgentes. Es por esto que en el discurso estatal se ignora el conflicto armado, pero lo grave de esta situación, no es sólo que se deforme la realidad, sino que se pase por encima de los miles de colombianos que directa o indirectamente han sido víctimas del conflicto. Por lo que un "pueblo alegre y trabajador, no hace que años y años de violencia desparezcan, ser el país de América Latina con más reinados de belleza no nos convierte en un pueblo esperanzado, todo lo contrario, más bien, en un pueblo anestesiado" (Trejos, 2008, p. 83).

\section{ANÁLISIS DE RESULTADOS}

Cuando Nietzsche manifiesta que «en cada acción está reproducida y abreviada la historia de todo acontecer» (Nietzsche citado en Heidegger, 2000, p. 330), se refiere precisamente a la repetición de lo mismo una y otra vez; al relacionar esta afirmación con el problema del conflicto sería un engaño negar que también esta problemática social se encuentra vinculada 
irremediablemente al devenir, a la secuencia ontológica que permite recrearse en el tiempo, a partir de diferentes formas de prolongación; frente a este modo de ser circular del conflicto que perpetúa las acciones propias del enfrentamiento entre grupos y busca a través de la conciliación, garantías para las partes involucradas. La historia de la violencia nos ha develado dimensiones y formas de combate, sumadas a la dificultad de medir la cantidad de daños psicológicos, fisicos corporales y materiales, a través de asesinatos selectivos, masacres en clave de estrategia para sembrar terror, degradación de la guerra encarnada en la sevicia y la tortura, despojos, extorsiones, secuestros, toma de rehenes, desarraigo, tristeza y desesperanza fundamentadas en el desplazamiento forzado, cuerpos grabados por la violencia sexual, reclutamiento forzado de menores, acciones bélicas que causan el uso de artefactos explosivos, entre otras consecuencias producto de la lógica, el crecimiento y las dinámicas del conflicto; sin embargo, mantenernos en la teorización del conflicto y la práctica de acciones del posconflicto, dejando de lado el carácter ontológico, es decir esencial del conflicto que es fundamentalmente finito y circular, nos impide también comprender la secuencia irremediable de la violencia en puntos de escape o fugas. Las fugas son las formas conocidas por los individuos que utilizan para continuar con las acciones violentas, sean estos, algún rebelde que no pretende detenerse $\mathrm{u}$ otro que vea beneficios personales, familiares y grupales en la conformación de alianzas, como el narcotráfico y el control a cargo de cierto grupo de una zona geográfica, con todo lo que esto implica.

Así pues, el interés inherente de continuar las acciones violentas como posibilidad de beneficio económico, material, fisico o simple placer, impide la prolongación en el tiempo de otro tipo de acciones, así como la construcción de una sociedad que se piense y se vea a sí misma como no violenta.

Pues, habida cuenta del inevitable entrelazamiento de las acciones humanas y de todas las cosas, no cabe impedir que mi acción afecte al destino de otros, de modo que poner el juego lo mío, implica siempre poner en juego algo que le pertenece a otro y sobre lo que propiamente yo no tengo ningún derecho. En toda acción (y también la omisión quietista lo es) hay que asumir este elemento de culpa. (Jonas, 1995, p. 77) 
A la idea que nos ilustra Hans Jonas sobre la vuelta de las acciones que con toda su fuerza son lanzadas hacia el futuro y que con la igual fuerza, en algún momento, se hará presente, se suma el carácter ontológico de las mismas, esto significa que la historia se recrea con las acciones que realizamos y en el "mero hecho de que hay deseos y miedos, anhelos y renuencias, esperanzas y temores, placeres y tormentos, y con ello cosas deseadas y no deseadas, en suma, que hay querer y que en todo querer hay la voluntad de ser" (Jonas, 1995, p. 96). Se requiere, por tanto, de algo más: de una comprensión ontológica que dialogue con la ética respecto de nuestras acciones, pero la tarea debe ser dada en cada individuo a partir del arraigo a la vida en la que interviene la existencia de otros para dar sentido a la suya propiamente. Esta obligación humana de todo individuo como parte de una comunidad ha sido de alguna manera perpetuada por los pueblos indígenas de América Latina, mediante una forma de coincidir del sujeto con el mundo, en una «realidad ontológica» enraizada en un horizonte de auténtica vitalidad; realidad documentada en la obra del filósofo argentino Rodolfo Kusch, quien rescata precisamente otros modos de ser que contradicen la lógica teórica, antropocéntrica e individualista desde los cuales se construyen las actuales estrategias de paz en el posconflicto; a propósito, Kusch prevé que:

Lo importante es lograr un hombre tipo, con su cristalización existencial, o sea su traducción al «aquí y ahora» de nuestra vida cotidiana. De él participaría libremente el hombre de carne y hueso de la selva o de la pampa, según su propia estructura. Se trata de elegir un tipo de hombre que nos brinde un tipo de vida real, encierre un ethos, una filosofia, un plan de vida. Pero debe ser medido según la honestidad con que cada individuo comprende la definición del todo y la logre incorporar en base a su autenticidad o la malogre en función de la ficción. (Kusch, 2000, p. 110)

En Colombia es posible valernos de esta ontología que vincula al hombre con la naturaleza, siempre y cuando nos apartemos de esa visión logocéntrica de fijar todo, de esta Europa, dice Kusch, que sólo se preocupa por fijarse en lo fijo y no en el devenir. Mientras que el mestizo, habiendo sido capaz de subvertir la lógica que se le ha impuesto, es decir, lejos de 
su ser autóctono, va a encarar la situación dada, siempre con la intención de volver a la tierra y lo que le fue enseñado. Con la misma fuerza, propia de los mestizos, tenemos la posibilidad de comprender que no solo los violentos llenos de tradiciones ajenas movidas por intereses individuales, sino la lógica bélica que los auspicia, también pueden ser revertidos y reemplazados por un ethos ontológico nacido del amor a la tierra y a todo lo que de ella brota. Es decir que no podemos quedarnos anclados a una forma particular de investigar y de comprender la diversidad de factores, de hechos, de presupuestos y de esencias en este caso del conflicto y del posconflicto colombiano. La dinámica de esta estructura social (incluyente de la familiar y personal) exige otras formas de estudio, de análisis y de expresión.

$\mathrm{El}$ análisis de nuestros crepúsculos, las interpretaciones de nuestros acordes, y las expresiones líricas (cultas o populares) deben hacer parte integral de los proyectos de investigación que no se limitan a especulaciones racionales, indagaciones cuantitativas, o trabajo de campo muchas de las veces sesgado a la visión del investigador o reducido a su campo de formación. Resulta necesario abrir la posibilidad a otras formas de indagación, interpretación y comprensión de la realidad. El sentipensar ontológico, por ejemplo, va abriéndose paso con una apuesta de comprensión lírica que da cuenta de estudios previos, interpretaciones interdisciplinares, y expresiones desde la complejidad integral del ser humano, como puede evidenciarse en "Ontología poética latinoamericana" (2016). En este sentido, también se presenta aquí uno de los resultados de la investigación acá avanzada:

No es suficiente pensar el conflicto:

nunca será suficiente teorizar la verdad.

La verdad de lo que es,

de lo que ha sido,

$y$ de lo que está siendo,

va más allá de toda buena teoría.

Si es verdad

se enraíza en el suelo,

y el investigador se hunde hasta las tripas, 
porque -verdadeante- busca

el sentido último y sentiente

de lo que acontece.

La geocultura de la violencia latinoamericana

nos hace mirar al paisaje.

También éste es un factor a tener presente.

$Y$ el paisaje nos devela el mestizaje

de una barbarie selvática y humana,

según lo señala Kusch.

La historia de nuestros conflictos

no puede reducirse

a meras categorías conceptuales

esbozadas desde un escritorio o desde un tablero.

Debemos estudiarnos

desde el fondo de nuestras tripas.

Debemos tener el valor

de romper los límites que nos imponen

ciertas políticas,

ciertas tradiciones culturales,

y cierta academia oficial y escolarizada.

La naturaleza no esconde sus impetus

así como la memoria no olvida

su sufrimiento.

Sanar el dolor de varias generaciones,

transformar la agresividad de tantos pueblos,

superar la violencia arraigada en el alma,

precisa de una terapéutica humana

en sentido espiritual.

El perdón no se le impone a nadie:

ningún pueblo perdonará

por la normatización legal

que inventan los políticos soñadores

del posconflicto. 
El poeta tiene algo que enseñarle al mundo.

El humanista tiene algo que ofrecerle al mundo.

¿Qué se les ha permitido decir a los humildes?

¿Dónde están las víctimas sin voz?

¡No se puede soñar con una paz barata!

(por más costosa que nos esté saliendo)

$\ldots$

;Ay!

¡El dolor no se cura con firmas sobre papel!

¡La violencia no se calma con políticas amañadas!

¡El conflicto no amaina con leyes insanas!

El paisaje natural de América Latina

- $y$ en este caso, de Colombia-

exige que sintamos el paisaje cultural

de nuestras verdades:

la verdad de todas las víctimas del conflicto, la verdad de todos los actores del conflicto, ¡la verdad de todos los silencios ocultados!

La paz es fruto de la justicia, y ésta todavía está lejana.

Sube a hablar conmigo

-gime el poeta-,

sube a hablar conmigo,

joh dolor americano!,

porque la sangre derramada

aún fluye por la corriente del río

$y$ clama justicia.

No es suficiente la verdad poca

de quienes se sientan a negociar la paz.

Los negocios no hacen justicia

y la injusticia no trae paz. 
Tampoco es suficiente la verdad poca

de quienes elaboran las categorías conceptuales

de los discursos oficiales

del posconflicto.

Así como tampoco es suficiente

esta ilación de versos

que se van soltando

en amaneceres cálidos y anocheceres húmedos.

Falta mucho camino,

falta mucha verdad.

Faltan muchos actores

a los que se quiere callar.

Nos corresponde sentipensar

nuestra realidad completa:

¡tarea ardua!,

pero inexcusable.

El ser de lo que somos

es mucho más complejo

de lo que imaginamos:

no despreciemos ninguna verdad.

Poco a poco

$y$ paso a paso

podremos alcanzar

una reforestación ambiental

geocultural.

Para una ontología de la no-violencia

debe darse antes

una ontología de la violencia,

de nuestras más diversas violencias,

asumiendo la más descarnada verdad,

porque sin las verdades todas

de todos los actores del conflicto

no alcanzaremos la verdadera paz. 
Esto

puede que no sea

más que el verso de un no poeta,

$y$ puede que sea

un poco verdad.

Pero las verdades

de todas las minorías

no deberían faltar:

ique no se jacten los poderosos!

\section{CONCLUSIONES}

No ha sido el propósito de nuestro proyecto de investigación lograr algunas conclusiones; en verdad, ni siquiera hemos aspirado a argumentar al menos una. El momento de transición entre conflicto y posconflicto exige, más que conclusiones, la práctica de un sumo cuidado. Ser cuidadoso resulta ser una exigencia indiscutible de quien sustenta el poder de propiciar la paz, el poder aportar y aportarse para la paz, el poder tener la sencillez de aceptar las razones ajenas. Comprender al otro, decía Kusch, me lleva a cambiar y a ceder algunos de mis argumentos. Sólo podremos vivir un verdadero posconflicto si aprendemos a comprender, y como fruto de esa comprensión devendrá seguramente el perdón, y con este perdón la paz. ¿Qué colombiano no ha soñado con la paz? Pero, a su vez, vale preguntar: ¿qué colombiano está dispuesto a jugársela por la comprensión del otro, para que entre los dos realicemos el sueño de la paz? El otro y yo, los otros conmigo constituimos el mestizaje geocultural de este suelo patrio que se llena de esperanza, pero que nos exige sacrificio. No vale soñar la vía fácil, lo que vale es estar dispuesto a darlo todo para poder lograr una paz verdadera: personal y socialmente justa, donde el poeta exprese con alegría la emoción del abrazo generado desde la sinceridad y en el sacrificio de todo egoísmo malsano. La ontología en América Latina también incluye, entonces, una ontología de la violencia, aquella que posibilitará la comprensión del ser verdadeante desde nuestras tripas: sentipensar ontológico. 


\section{REFERENCIAS}

Centro de Memoria Histórica, (2013) ¡Basta ya; Memorias de guerra y dignidada. Versión virtual. Recuperado de: www.centrodememoriahistorica.gov.co/micrositios/infor meGeneral/descargas.html

Cepeda H., J. (2016). Ontología poética latinoamericana. En Estamos siendo. Ontología en poetas latinoamericanos. Bogotá, Colombia: Ediciones USTA.

Heidegger, M. (2000). Nietzsche I (1936-1939). Barcelona, España: Ediciones Destino.

Heidegger, M. (2000). Nietzsche II (1936-1946). Barcelona, España: Ediciones Destino.

Jonas, H. (1995). El principio de responsabilidad. Barcelona, España: Herder.

Kusch, R. (2000). La seducción de la barbarie. En Obras completas Tomo I. Rosario, Argentina: Ross.

La Bitácora Urbano/Territorial. (2008). Ciudad y hábitat en el postconflicto en Colombia y el mundo, de la Universidad Nacional de Colombia, Recuperado de: www.revistas.unal.edu.co/index.php/bitacora/article/view/53175/html00

Martínez, C. (2013). Ley de víctimas y restitución de tierras en Colombia en contexto. Berlín, Alemania: Forschungs- und Dokumentationszentrum Chile-Lateinamerika - FDCL e.V.

Human Rights Watch. Informe mundial 2017. Colombia. Edición digital. Recuperado de: www.hrw.org/es/world-report/country-chapters/298516

Springer, N. (2012) Como corderos entre lobos. https://www.centrodememoriahistori ca.gov.co/descargas/informe_comoCorderosEntreLobos.pdf

Trejos, F. (2008), Negación del conflicto armado interno, como eje del discurso constructivista del estado colombiano en la construcción de la identidad nacional contemporánea (19642004), Revista Encrucijada Americana.Año 2. No 1 Otoño-invierno, Recuperado de: http://132.248.9.34/hevila/Revistaencrucijadaamericana/2008/no1/5.pdf 
